\begin{tabular}{|l|l|}
\hline Factores clave para entender la violencia en El Salvador & Titulo \\
\hline Salgado, Melissa - Autor/a & Autor(es) \\
\hline El prisma de las seguridades en América Latina. Escenarios regionales y locales & En: \\
\hline Buenos Aires & Lugar \\
\hline CLACSO & Editorial/Editor \\
\hline 2012 & Fecha \\
\hline $\begin{array}{l}\text { Política de seguridad; Desigualdad social; Estructura económica; Historia económica; } \\
\text { Análisis histórico; Violencia; Delitos; Homicidio; El Salvador; }\end{array}$ & Temas \\
\hline Capítulo de Libro & Tipo de documento \\
\hline http://bibliotecavirtual.clacso.org.ar/clacso/gt/20120412115538/prisma-3.pdf & URL \\
\hline $\begin{array}{l}\text { Reconocimiento-No comercial-Sin obras derivadas 2.0 Genérica } \\
\text { http://creativecommons.org/licenses/by-nc-nd/2.0/deed.es }\end{array}$ & Licencia \\
\hline
\end{tabular}

\begin{tabular}{|c|}
\hline $\begin{array}{c}\text { Segui buscando en la Red de Bibliotecas Virtuales de CLACSO } \\
\text { http://biblioteca.clacso.edu.ar }\end{array}$ \\
Consejo Latinoamericano de Ciencias Sociales (CLACSO) \\
Conselho Latino-americano de Ciências Sociais (CLACSO) \\
Latin American Council of Social Sciences (CLACSO) \\
www.clacso.edu.ar
\end{tabular}
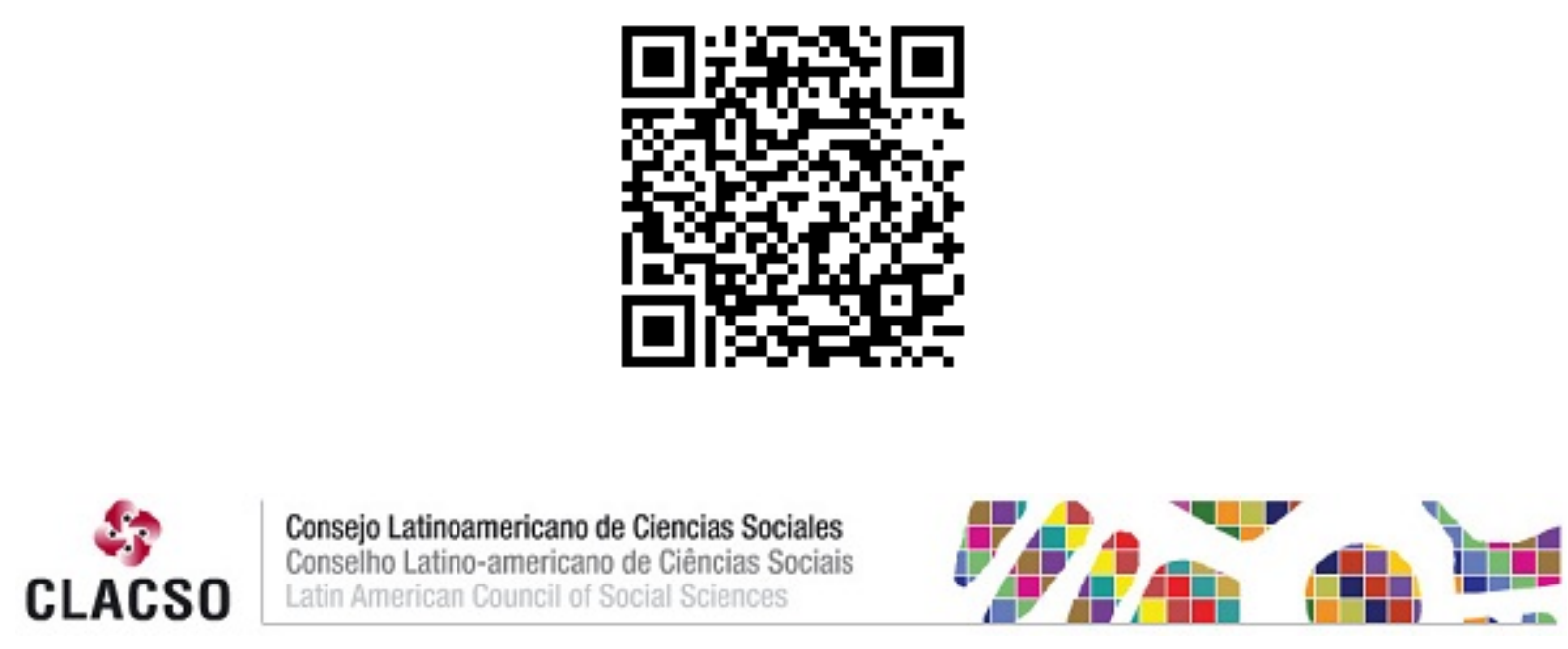
Melissa Salgado*

\section{FACTORES CLAVE PARA ENTENDER \\ LA VIOLENCIA EN EL SALVADOR}

\section{INTRODUCCIÓN}

El presente trabajo tiene como finalidad presentar algunos aspectos de la enorme complejidad de la violencia en El Salvador. Al tratarse éste de un fenómeno social multicausal, dar una explicación exhaustiva se convierte en un reto que rebalsa el alcance de una sola disciplina científica. Sin embargo, en este escrito trato de resaltar, según mi juicio, algunas presiones estructurales - construidas en la historia reciente y manifestadas en el modelo económico vigente y la impunidad institucionalizada- que impulsan y fortalecen cada día más el problema de la violencia que aqueja El Salvador y lo convierten en el país más violento, según la tasa de homicidio, de América Latina.

En este sentido, los niveles de análisis del artículo se pueden resumir en dos: el primero, con énfasis en lo particular y singular del caso de la violencia en El Salvador y que se encuentra en su historia del siglo $\mathrm{XX}$, y el uso de la violencia como medida de resolución de conflicto para la permanencia del régimen político adoptado; y un segundo nivel, que describe la parte generalizable y endógena de la violencia, enfocado

* Investigadora y docente del Departamento de Economía de la Universidad Centroamericana José Simeón Cañas (UCA) El Salvador. Correo electrónico: <melissa. salgado@gmail.com>. 
en la estructura económica y, sobre todo, en lo restrictivo de los canales de distribución que pone en juego la reproducción social de la población salvadoreña bajo un marco institucionalizado de la impunidad.

\section{LA HISTORIA QUE EXPLICA LA VIOLENCIA SALVADOREÑA}

Sin el afán de realizar una reconstrucción histórica en el sentido estricto, el presente artículo parte del proceso de acumulación originaria de capital en El Salvador, establecido en torno al cultivo del café a finales del siglo XIX y principios del XX. La importancia de este punto de partida se concentra en la implementación del modo de producción capitalista como el sistema de organización social dominante y la consolidación de uno de los principales problemas estructurales del país: la enorme desigualdad en la distribución de los ingresos.

Durante este proceso de acumulación originaria de capital, la producción a gran escala del café impulsó a que una élite del sector poblacional para que asumiera el control de al menos un $40 \%$ de la superficie total del país, mientras miles de pequeños agricultores fueron desplazados de las tierras que habían cultivado durante años (Acevedo, 1999: 42).

Alrededor del proceso de expansión del café se delinearon los trazos generales del sistema económico y se anudaron los rasgos de sus relaciones fundamentales. Las modificaciones en la forma de propiedad, la estructura de la tenencia de la tierra, las formas de explotación agrícola y el carácter del empleo adquirieron los elementos centrales de su configuración alrededor del cultivo cafetalero (Gordon, 1989:17).

En este sentido, la gran propiedad cafetalera explica en parte la importancia social, política y económica que han conservado los sectores agrarios de la clase social dominante, sin que éstos hayan propuesto un proyecto político y social en torno al cual se hayan aglutinado otras clases y sectores de clase de la sociedad (Gordon, 1989: 29), marcando así la historia de la desigualdad en el nivel de ingresos que ha caracterizado por larga data a El Salvador.

Ante este contexto de consolidación del modelo económico mono-agroexportador, los efectos de la crisis de 1930 se hicieron presentes en la economía salvadoreña a través de la caída del precio internacional del café, la recesión de los Estados Unidos y su disminución en el nivel de importaciones del producto, la caída de la producción cafetalera y su impacto en la disminución del empleo, menores ingresos estatales, entre otros aspectos que reforzaron los anhelos de la inmensa mayoría de la población subsumida en la miseria de exigir un nuevo orden de tenencia de tierra.

Por su parte, la crisis también implicó el incremento del cultivo del café a gran escala y el surgimiento de latifundios, hecho que impulsó, en 1932, un levantamiento indígena-campesino reivindicando zonas donde 
cultivar. La represión estatal que desató el alzamiento tuvo como resultado una masacre de más 30 mil vidas -suceso histórico conocido como la Masacre del 32- y a su vez representó el inicio de una dictadura militar que marcaría los siguientes 44 años de historia política en El Salvador.

Los efectos de la Masacre del 32 fueron de tal envergadura que muchos de ellos son perceptibles en la actualidad: el silencio manifiesto de la expresión cultural indígena de El Salvador ${ }^{1}$; el nacimiento del "comunismo" como identitario de cualquier tipo de oposición a los establecimientos de la clase dominante, y ahora de la milicia; la implementación del paramilitarismo en la zona rural. De este modo, la Masacre del 32 se convierte en la institucionalización, a través del Estado, del uso de la violencia como mecanismo de control social y político (Lungo, 2008: 45).

La consolidación del nuevo panorama político se desarrolla alrededor de la oligarquía cafetalera respaldada por la dictadura militar, bajo la condición que el marco institucional de los militares cuidara de los intereses propios del modo de acumulación de la época. Aunque esta simbiosis tuvo sus reveses ocasionales, según lo reflejan los múltiples golpes de Estado y fraudes electorales de la época, siempre primaron los intereses de la clase dominante.

No hay que perder de vista que, desde la dictadura militar en El Salvador, la represión estatal representó, continuamente, el mecanismo de resolución de conflicto contra todo lo relacionado a manifestaciones de oposición, descontento social, exigencias de mejoras de condiciones de vida y de Derechos Humanos.

Luego de la Segunda Guerra Mundial se da una evolución de los precios de los granos básicos, permitiendo que El Salvador diversificara sus exportaciones agrícolas con la introducción de la caña de azúcar y el algodón, hecho que agudizó aun más la concentración de la tierra en pocas manos: "[...] en los años sesenta el coeficiente de Gini de concentración de la tierra había llegado a 0,83, el más alto de América Central [...] y uno de los cinco más altos del mundo" (Acevedo, 1999: 44).

Durante los primeros cincuenta años del siglo XX, es decir, desde la consolidación del proceso originario de acumulación de capital hasta la diversificación de los cultivos, el modelo de producción presentó un dualismo en la dinámica de la demanda de trabajo: por un lado, requería de una fuerza de trabajo temporal con base en las estaciones de los cultivos y, por el otro, obligaba a esta misma mano de obra a desarrollarse en un sector de subsistencia, auto empleándose en los

1 Los indígenas cambiaron sus apellidos, dejaron de hablar náhuatl, cambiaron sus vestimentas por ropa de ladinos, entre otros aspectos. 
periodos del año en que el modelo productivo no necesitaba fuerza laboral, "el modelo de crecimiento económico combinó el desarrollo del sector agroexportador con el subdesarrollo del sector subsistencia. Ambos sectores estaban conectados por un sistema de contratación estacional" (Acevedo, 1999: 46).

Posteriormente, durante los años cincuenta, se inició un proceso de industrialización con el propósito de sustituir las importaciones con productos nacionales. Este modelo de industrialización orientada a la sustitución de importaciones -el modelo productivo ISI-, bajo pleno respaldo del Estado oligárquico militar, adoptó una política intensamente proteccionista, con exenciones fiscales y aplicación discrecional de aranceles, así como inversiones cuantiosas en obras de infraestructura para reducir los gastos del sector industrial.

A pesar de estos incentivos, en las primeras etapas del proceso de desarrollo industrial surgió un obstáculo importante: las grandes limitaciones al crecimiento del mercado nacional impuestas por la distribución desigual de los ingresos y la estructura salarial asociada al modelo de agroexportación, como resultado de las cuales la mayor parte de la población carecía del poder adquisitivo necesario para generar una demanda suficiente de productos industriales (Acevedo, 1999: 48). Dicho problema se resolvió en un primer momento con la creación del Mercado Común Centroamericano (MCCA).

La importancia del MCCA para El Salvador residió en el hecho de representar, entre los países centroamericanos, el mayor mercado para sus bienes manufactureros, permitiendo que el país obtuviera superávit comerciales en la región centroamericana: "los puntos centrales del Tratado General estipulaban la libre circulación de bienes, personas y capitales; implantaban un arancel uniforme con respecto a los países ajenos al área centroamericana y abatían las barreras aduanales en el interior de la región" (Gordon, 1989: 39). Sin embargo, este nicho de mercado se vio finalizado en 1969 con la "Guerra de las 100 horas" contra Honduras que, si bien fue ganada militarmente por El Salvador, en términos económicos resultó ser el gran vencido.

En este sentido, el modelo productivo ISI, ante la incapacidad de realización en el mercado doméstico, no logró paliar directamente los problemas de distribución de ingresos, sino que terminó por reproducir, en los núcleos urbanos, las desigualdades que prevalecían en las zonas rurales (Acevedo, 1999: 50).

Otro aspecto a enfatizar de este periodo del modelo productivo ISI es la consolidación de una clase media urbana asociada a la industrialización que, ante la ilegitimidad del sistema político militar, incrementaba la radicalización de su postura política. Como respuesta a este panorama, el Estado oligárquico militar respondió con una 
oleada de represión a través de la Ley de Protección y Garantía del Orden Público (Acevedo, 1999: 53).

A lo largo de la década de los setenta se desarrolló en El Salvador una profunda crisis política. Caracterizada por el deterioro creciente de los canales e instrumentos de negociación del Estado, por la progresiva erosión de los mecanismos de control de los sectores subordinados, y por la pérdida de fuerza de las posiciones centristas, la crisis desembocó en la formación de un vasto movimiento popular: el Frente Farabundo Martí para la Liberación Nacional (FMLN), que alcanzaba su cima en 1979-1980 (Gordon, 1989: 13).

Como consecuencia de la radicalización política por parte de varios sectores sociales (clase media, maestros, estudiantes, campesinos, entre otros) y la represión institucionalizada del Estado, se inicia la guerra civil en El Salvador que marcaría los siguientes 12 años de historia del país,

la ofensiva militar lanzada por el FMLN el 10 de enero de 1981 marcó el comienzo oficial del conflicto armado. [...] Sin embargo, era simplemente la culminación de las grandes presiones socioeconómicas y políticas que se venían acumulando desde hacía varias décadas en la sociedad salvadoreña y que los sucesivos gobiernos militares fueron incapaces de disipar (Acevedo 1989: 53).

Es así como, durante la década del ochenta, la economía salvadoreña se vio inmersa en la crisis económica, política y social más profunda de su historia. A las consecuencias del conflicto armado como tal, que cobró, entre otras cosas, la vida de más de 75 mil personas, provocó la destrucción de obras de infraestructura valoradas en millones de dólares y redujo significativamente la inversión, se le sumaba la crisis económica mundial reconocida como "la década perdida", dando así un impulso externo a la situación tan adversa que vivía el país.

Con la llegada de ARENA al poder estatal en 1989 se cimientan las bases para el cambio de modelo económico fundamentado en la liberalización de la economía, pero no es hasta la firma de los Acuerdos de Paz, el 16 de enero de 1992, que se logra su implementación. Es decir, hasta alcanzado el periodo de paz es que El Salvador transfigura su estructura económica e institucional a través de tres aspectos, principalmente: 1) las privatizaciones de casi todas las empresas estatales (a excepción del agua, el sistema de salud, acceso a redes viales y la lotería); 2) las reformas tributarias como la eliminación del impuesto al patrimonio y de los techos escalonados del impuesto sobre la renta, así como la implementación del impuesto sobre el valor agregado; y 3) la liberalización de la economía, centrada en la desregulación de precios (principalmente, en granos básicos y petróleo), la liberalización del tipo de cambio, la 
eliminación abrupta de aranceles en los primeros dos periodos de gobernación y, en los últimos años, la firma de una serie de Tratados de Libre Comercio dentro de los que destacan -por las enormes asimetrías socioeconómicas- el firmado con Estados Unidos y, aún en proceso de negociación, el tratado con la Unión Europea (Lazo, 2005: 11).

Las políticas económicas implementadas por ARENA se formularon bajo la lógica del desarrollo económico a través del comercio exterior, en la que la nueva transformación económica fortalecería al sector productor de los bienes transables (específicamente, la manufactura) que absorbería la mayor cantidad de mano de obra y, por consiguiente, representaría el pivote dinamizador del resto de la economía salvadoreña, todo ello enmarcado en el fomento de la competencia y productividad que trae consigo el comercio exterior.

Pero la realidad económica y social salvadoreña tras el conflicto bélico no dio muestras de la incorporación al dinamismo internacional a través del sector secundario marcado por el comercio exterior, sino todo lo contrario: fue el sector terciario y los bienes no transables los que presentaron mayor crecimiento económico.

Con todo lo expresado anteriormente, se destaca que, en la historia reciente de El Salvador, fueron tres los modelos productivos aplicados: la agroexportación, la industrialización por sustitución de importaciones y la liberalización de la economía. Dichos modelos de producción se vieron amparados por procesos de institucionalización política distintos. A los dos primeros modelos les correspondió un régimen de dictadura militar con una fuerte intervención del Estado en la economía que culminó en la guerra civil. El último modelo productivo -vigente en la actualidad- es el que se basa en la apertura comercial, bajo el marco institucional de la democracia procedimental y bajo el régimen del mercado como distribuidor de recursos.

A su vez, es preciso enfatizar que la historia de El Salvador del siglo XX está caracterizada por una enorme estrechez en la distribución del ingreso, lo cual condiciona a una sociedad con enormes procesos de desigualdad y exclusión social; por canales de negociación, diálogo y debate público cerrados; por el fantasma del comunismo como identitario de cualquier expresión de oposición a los establecimientos políticos dominantes y por la institucionalización de la violencia como mecanismo de resolución de conflicto.

Cada uno de estos elementos contribuyen a explicar la situación de violencia de El Salvador y denotan la persistencia de las condiciones que propulsan a una creación de valores y normas sociales que legitiman y privilegian el uso de la violencia en cualquier ámbito por sobre otras formas de comportamiento social (Cruz y González, 1997), y al 
establecimiento institucional de un ordenamiento desigual de los recursos bajo el amparo de una fuerza coactiva para hacerlos respetar, por lo que el uso de la violencia es legítima, siempre y cuando garantice el mantenimiento de los cánones del orden social establecido (Baró, 2003: 121). Esto último sugiere la aplicabilidad de los conceptos de cultura de la violencia y violencia estructural para el caso de El Salvador.

\section{EL PERIODO DE LA POSGUERRA: ¿TIEMPO DE PAZ O VIOLENCIA?}

\subsection{PUNTO DE PARTIDA DEL PERIODO DE POSGUERRA}

\subsubsection{La Ley de Amnistía General para la consolidación de la "paz"}

Si bien la firma de los Acuerdos de Paz, firmados el 16 de enero de 1992 en el castillo de Chapultepec, México D.F., representó el gran momento de reconciliación entre las partes involucradas en el conflicto armado, este proceso se vio interrumpido por la Ley de Amnistía General para la Consolidación de la Paz.

El día 15 de marzo de 1993 la Comisión de la Verdad² publicó el informe titulado: "De la locura a la esperanza: la guerra de 12 años en El Salvador", documento en el cual se especificaban algunos de los crímenes de guerra cometidos durante el conflicto. No obstante, el día 20 de marzo del mismo año se emitió el Decreto $\mathrm{N}^{\circ} 486$ Ley de Amnistía General para la Consolidación de la Paz, que se constituyó en ley el día 22 de marzo.

Vigente esta ley, nunca se llevó a cabo investigación alguna desde los órganos de Justicia del Estado salvadoreño sobre los crímenes de guerra en general, así como los crímenes de Lesa Humanidad (entre estos últimos, el asesinato de monseñor Arnulfo Romero, en 1980; y los seis sacerdotes jesuitas, en 1989), a pesar de los detalles sobre los responsables que recabó y publicó el Informe de la Comisión de la Verdad.

La Ley de Amnistía se presupone de vital importancia para la reconciliación nacional y el restablecimiento de las condiciones para la consolidación de la paz en El Salvador. Otorgó la amnistía absoluta e incondicional a todas aquellas personas y cómplices involucrados en crímenes que no sobrepasaran a las veinte víctimas, a pesar de haberse iniciado o no una sentencia judicial (Inciso IV. Decreto $N^{\circ} 486$ ).

$\mathrm{El}$ alcance y envergadura de dicha ley, no obstante, fue de tal magnitud que tuvo como resultado la legitimación de la impunidad a todo nivel social, permeando de esta manera el imaginario colectivo de la

2 Organismo establecido por las Naciones Unidas en los Acuerdos de Paz para investigar las violaciones a los Derechos Humanos ocurridas durante el conflicto armado. 
población "que cualquier acto no tiene consecuencias". En este sentido, una de las principales características del periodo de la posguerra es la impunidad.

De esta forma, las estructuras de la violencia inmersas en la sociedad salvadoreña se mantienen pero ahora en el marco de la democracia.

\subsubsection{El modelo de desarrollo económico implementado}

La estructura económica del país [El Salvador], de no sufrir cambios fundamentales, mantendrá el actual clima de inseguridad, frustración, ira e impotencia y probablemente de confrontación [...] (López Vallecillos, 1976: 30).

Por otra parte, en términos de la estructura económica, El Salvador no contaba con las condiciones para un tipo de modelo productivo cuyo patrón de crecimiento y desarrollo económico estuviera cimentado en la liberalización de la economía, dado los requerimientos de alta competitividad nacional ${ }^{3}$ que implica la dinámica del comercio exterior.

Pero es en este contexto que se abre paso al nuevo modelo de desarrollo económico, el neoliberalismo, a través de los Programas de Ajuste Estructural (PAE) y los Programas de Estabilización Económica (PEE), los cuales no reconocían los problemas -políticos, sociales, económicos e institucionales- estructurales propios, y el contexto de guerra civil por los que cruzaba la nación. A su vez, ignoraba las posibles presiones adversas del comercio internacional en materia de distribución de ingreso en la sociedad salvadoreña, dada su posición en la división internacional del trabajo.

En este sentido, podemos decir, como Alexander Segovia, que:

[...] aunque El Salvador tiene problemas estructurales similares a los de muchos otros países con un grado de desarrollo similar, hay una diferencia importante en una transición posbélica: el país debe llevar a cabo un proceso de estabilización y reforma económica al mismo tiempo que intenta la doble transición de la guerra a la paz y de un régimen autoritario a un sistema democrático (Segovia, 1999: 75).

Es así como, dadas las condiciones y el contexto en el que se encontraba El Salvador, es cuestionable el apresuramiento con el que se aplicó

3 Que se traduce en fuerza de trabajo calificada, avances tecnológicos aplicados a los procesos productivos, infraestructura adecuada, marcos legislativos e institucionales propios para el incentivo del crecimiento económico, entre los principales. 
el modelo económico con base en la liberalización económica, hecho incluso anunciado por instituciones como la CEPAL:

Tal vez sea necesario [...] prorrogar un poco el plazo para [...] proceder en forma menos enérgica con la liberalización comercial. La adopción de metas cuantitativas más flexibles para el programa de estabilización, dentro de ciertos límites, podría ser un sacrificio aceptable, ya que ayudaría a alcanzar la meta más imperiosa de garantizar la gobernabilidad de una sociedad que, durante años, ha estado sumido en una guerra civil desastrosa (Boyce, 1999: 182).

La muestra de la estrechez de los canales de distribución en la estructura económica salvadoreña se detalla en el mercado laboral, tal como se presenta en el gráfico siguiente:

\section{Grafico 1}

Población ocupada y cotizante

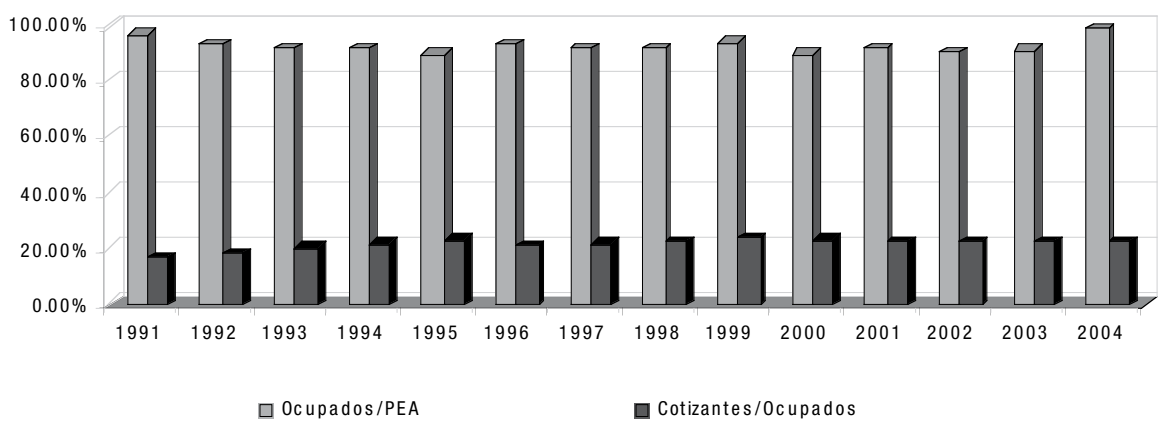

Fuente: elaboración propia con base en Dirección General de Estadísticas y Censos (DIGESTYC), y planilla mensual de cotizantes del Instituto Salvadoreño del Seguro Social (ISSS).

De acuerdo con el Gráfico 1, el nivel de ocupación con respecto a la PEA a lo largo del periodo analizado es cercano, en promedio, al 90\%. Esto indica que el desempleo abierto no representa un problema en el mercado laboral salvadoreño. Sin embargo, el número de trabajadores categorizados en el sector formal en rigor, medido por el acceso a seguridad social, apenas representa un poco más del $20 \%$ de los ocupados para el año 2006. Este hecho apunta a que el mercado laboral del país se encuentra inmerso en el subempleo o en actividades laborales de baja productividad, poca remuneración, sin horarios de trabajo, sin vacaciones, sin prestaciones sociales, sin sistema de pensión (Salgado, 2009: 37).

En términos de distribución salarial (ver Gráfico 2) en el mercado laboral formal, el modelo económico ha mantenido la estructura de inequidad en 
su repartición. En este punto se resalta que los salarios mínimos reales ${ }^{4}$ han erosionado en forma drástica su capacidad de compra y no se recuperan a los niveles que se registraban a finales de los años ochenta (Salgado, 2009).

\section{Gráfico 2}

Salario mínimo urbano real (Índice $2000=100$ )

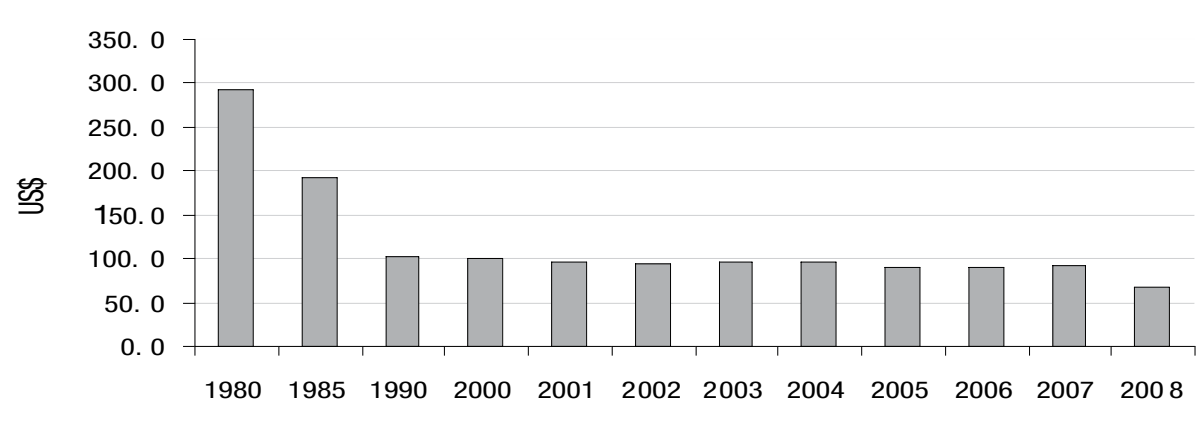

Fuente: elaboración propia, con base en CEPAL e información oficial.

Volviendo entonces al problema original, los canales de distribución del ingreso no se ampliaron en el marco de este nuevo modelo económico y de período de paz. Hecho que, como se detallará más adelante, se convierte en una de las características persistentes en las zonas de mayor violencia del país.

En este sentido, El Salvador cuenta con la existencia de condiciones que sustentan un conflicto social en términos de supervivencia humana, que bien se representa por la violencia estructural. En otras palabras, se trata de una violencia inherente a la forma en cómo se organizó social y económicamente la sociedad salvadoreña.

El término de violencia estructural contiene una carga valorativa y explicativa determinante $[\ldots]$ como el resultado de un conflicto entre dos o más partes [haciendo referencia a las clases sociales involucradas] en el que el reparto, acceso o posibilidad de uso de los recursos es resuelto sistemáticamente a favor de alguna de las partes y en prejuicio de las demás (La Parra y Tortosa, 2003: 63).

\section{2 ¿TIEMPO DE PAZ O VIOLENCIA?}

Irónicamente, es en el periodo de "paz" donde se ubica el mayor registro de violencia en El Salvador, que lo ha llevado a ser catalogado como

4 Los salarios mínimos, en buena medida, representan la remuneración del empleo formal por ser los salarios que más se repiten en la planilla salarial, lo cual a su vez nos indica la poca calificación de la fuerza de trabajo salvadoreña. 
uno de los países más violentos de Latinoamérica. Y de acuerdo al Informe "Abrir espacios a la seguridad ciudadana y el desarrollo humano", presentado por el Programa de las Naciones Unidas para el Desarrollo (PNUD), El Salvador, junto a Guatemala y Honduras, es clasificado como la región (de países sin conflicto armando) más violenta del mundo.

Sin el afán de reducir la violencia únicamente a los asesinatos, pero reconociendo que se trata del indicador más execrable de violencia $^{5}$ que tiene un país, a continuación se presenta la evolución de los homicidios en El Salvador.

\section{Gráfico 3}

Homicidios

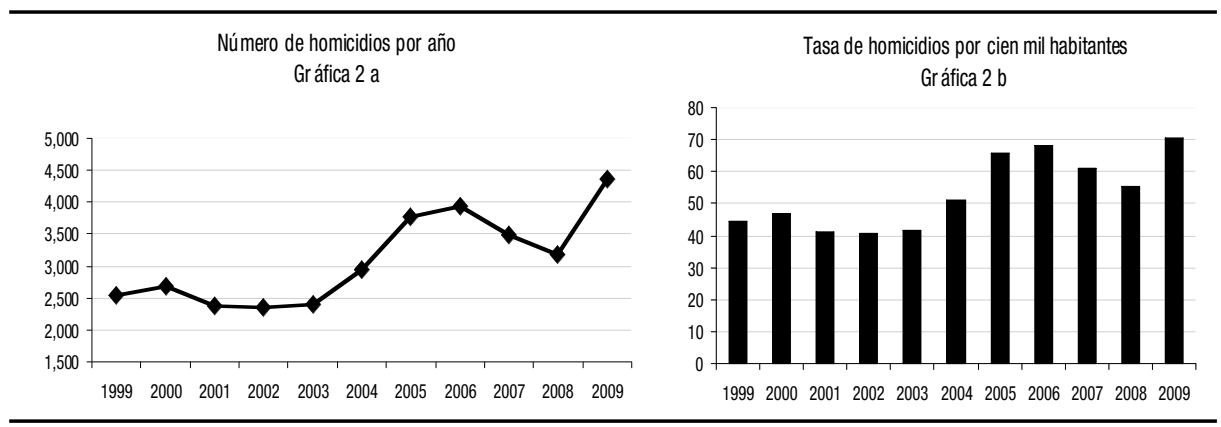

Fuente: elaboración propia, basada en Díaz Gallegos et al. (2009: 33).

Nota: para el cálculo de la tasa de homicidios, la población entre 1999 a 2006 se basa en el censo poblacional de 1992; para el resto del periodo se utilizó el censo poblacional del año 2007. Cálculo propio para el año 2009.

Tal como lo muestran las gráficas del panel anterior, el repunte de los homicidios en El Salvador se da a partir del año 2004, año que presentó una tasa de crecimiento de $22,8 \%$ con respecto al año anterior y una tasa de homicidios que se posicionó en 51,1 cada 100 mil habitantes. Desde ese año se registran entre 8 y 12 homicidios diarios. Asimismo, se resalta que el año 2009 se ubica como el más violento registrado en décadas, con una tasa de homicidio de 70,4 cada 100 mil habitantes.

Es preciso resaltar que el crecimiento acelerado de los homicidios coincide con la aplicación de los planes "antidelicuenciales" llamados: Mano Dura (2003), Súper Mano Dura (2004) y el Plan Sarissa (2007). Los objetivos de dichos planes fueron la reducción de la "delincuencia" con especial énfasis en la reducción de los homicidios. No obstante, los resultados (ver Gráfico 3) fueron todo lo contrario a los propósitos.

Ahora bien, ¿por qué fracasaron dichos planes? Entre otros factores, uno de los puntos clave que ayuda a responder la pregunta, se

5 Las expresiones de violencia que más se registran en El Salvador, son: homicidios, extorsiones, robo, hurto, lesiones, violencia intrafamiliar, violencia sexual y secuestro. 
encuentra en la concepción de la violencia del cual partieron dichos planes. Específicamente, los planes Mano Dura y Súper Mano Dura identificaron la violencia con delincuencia y con ello a "las maras", eludiendo de esta forma lo que se conoce como los delitos silenciados ${ }^{7}$.

Con esto último, los planes antidelincuenciales enfrentaron únicamente la parte visible de la violencia, que a su vez, fomentaron la identificación de la violencia con la clase social más pobre, específicamente con los jóvenes, hombres entre 14 y 24 años de edad.

Por otra parte, es preciso resaltar uno de los principales hallazgos del estudio de Díaz Gallegos et al. (2009) en los que se detallan las características socioeconómicas más relevantes de las zonas que registran mayores expresiones de violencia, entre los que se encuentran: mayor PIB per capita, mayor ingreso familiar, menor índice de pobreza humana, mayor desocupación, y mayor índice de desarrollo humano. Estas variables nos indican, en un principio, que la pobreza no es generadora de violencia en El Salvador, y nos sugiere que el contraste entre clases sociales en un contexto de distribución inequitativa del ingreso, exclusión y marginación social, sí puede presionar en niveles elevados de violencia.

No es la pobreza, la falta de educación lo que determina el mayor o menor grado de inseguridad en los países, sino la desigualdad social. Las sociedades de consumo proponen, en lo formal, las mismas metas para todos, pero en la práctica, sólo algunos las pueden alcanzar. La frustración, la violencia, el delito son los frutos de la desigualdad (Kreimer, 2008: 1; citado por Díaz Gallegos et al., 2009: 111).

\section{CONCLUSIONES}

Una característica que persiste en la estructura económica salvadoreña es la inequidad en la distribución del ingreso, es decir, la estructura productiva tal cual se ha desarrollado en sus distintos modelos no logra canalizar y garantizar la reproducción social, por lo que se vuelve en un punto reiterativo en todos los conflictos sociales que se han desencadenado en la historia contemporánea de El Salvador y confirma las condiciones necesarias para el desarrollo de violencia estructural.

Sin lugar a dudas, la historia contemporánea tiene muchos elementos que nos ayudan a explicar la situación de violencia actual. Los

6 De acuerdo con el "Anuario estadístico" las defunciones por homicidios en El Salvador, según el Instituto de Medicina Legal (IML), del total de homicidios cometidos, las maras son responsables del 30\% aproximadamente, el $60 \%$ se desconoce, y el 10\% se ubica entre otros factores.

7 Dentro de los que se encuentran: corrupción, narcoactividad, crimen organizado, etcétera. 
puntos más certeros son: la Masacre del 32, la dictadura militar de casi medio siglo XX y la desembocadura del conflicto político en la guerra civil. Son hechos que marcan a la sociedad salvadoreña, en los patrones de dependencia de resolución de conflicto, de hacer uso de la violencia, cualquiera que sea el objetivo.

Los Acuerdos de Paz, el gran momento de reconciliación que pudo haber sostenido la sociedad en su conjunto con las autoridades estatales y clase social dominante, no se llevo a cabo por dos aspectos principalmente: la Ley de Impunidad y el modelo de desarrollo, tan agresivo que en nada corregía el principal problema estructural: desigualdad social. La impunidad en El Salvador llega a tal grado que para dar indicios de aclaración en el marco del sistema judicial internacional, más no en el nacional, de los grandes magnicidios de Monseñor Romero y los seis jesuitas, tuvieron que pasar entre 30 y 20 años, respectivamente.

La premura de soluciones inmediatas contra la violencia que se reflejen, al menos, en la disminución de asesinatos diarios, parten de una premisa en particular y es la de identificar a la violencia como sinónimo de delincuencia, por lo que la solución es el ataque frontal de las autoridades contra los "malhechores".

No obstante, en el momento de establecer la dicotomía autoridad/ delincuencia se dejan a un lado otros factores que también inciden de forma directa en la situación de la violencia del país, entre los que se encuentran: el crimen organizado, la criminalidad de cuello blanco, la impunidad, la intolerancia, la amnistía de los crímenes de Lesa Humanidad cometidos en la guerra civil, corrupción, el mismo negocio de la violencia, los patrones de resolución de conflictos, la violencia intrafamiliar, entre otros. Factores que no son contemplados en los planes "antidelincuenciales" y que, por lo tanto, lejos de disminuir los niveles de violencia los incrementaron.

Los planes antidelincuenciales, implementados desde el año 2003, enfrentan la cara visible de la violencia, pero no contemplan la plataforma que mantiene dicha estructura en funcionamiento. Al mismo tiempo, en dichos planes se tipifica y estigmatiza quién es considerado como delincuente, que dicho sea de paso, se identifica con hombres, jóvenes, en determinados estratos sociales, con un nivel determinado de educación, entre otros aspectos, cuyo representante máximo se encuentra en las "pandillas o maras".

\section{BIBLIOGRAFÍA}

Acevedo, Carlos 1999 “Antecedentes históricos del conflicto" en Boyce, James (coord.) Ajuste hacia la Paz. La política económica y la reconstrucción de posguerra en El Salvador (México: Plaza y Valdez/PNUD). 
Alvarenga, Patricia 1996 Cultura y ética de la violencia: El Salvador 1880-1932 (El Salvador: EDUCA).

Baró, Ignacio Martín 2003 Poder, ideología y violencia (Madrid: Trotta).

Cruz, José Miguel y González, Luis Armando 1997 Sociedad y violencia: El Salvador en la post-guerra (San Salvador: IUDOP-CIDAI/UCA).

Díaz Gallegos, Wilfredo José et al. 2009 “Territorialización de las expresiones de violencia y del gasto público destinado a seguridad ciudadana: policía nacional civil 2006-2008". Tesis de grado. Universidad Centroamericana José Simeón Cañas (UCA), El Salvador.

Gordon, Sara 1989 Crisis politica y guerra en El Salvador (México: Siglo XXI/UNAM).

La Parra, Daniel y Tortosa, José María 2003 "Violencia estructural: una ilustración del concepto" en Documentación social (Madrid), № 131.

Lazo, Francisco 2005 "Las principales transformaciones económicas experimentadas en El Salvador 1989-2003" en Democracia, análisis político y cultural $1^{\circ}$ de octubre.

López Vallecillos, Ítalo 1976 "Reflexiones sobre la violencia en El Salvador" en Revista de Estudios Centroamericanos, $\mathrm{N}^{\circ} 327-328$, enero-febrero.

Lungo, Irene 2008 "Castillos de Arena. Hegemonía y proyecto de derecha en El Salvador (1989-2004)". Tesis de maestría. FLACSO-México.

Programa de las Naciones Unidas para el Desarrollo 2010 "Informe sobre desarrollo humano para América Central. Abrir espacios a la seguridad ciudadana y el desarrollo humano" (s/d: IDHAC/PNUD).

Martínez Peñate, Oscar 1996 El Salvador democracia y autoritarismo (El Salvador: Nuevo enfoque).

Montesino, Mario 1998 Flexibilización del mercado laboral en El Salvador (El Salvador: FUNDE y SAPRIN).

Salgado, Melissa 2009 "Apertura comercial: impactos en la generación de empleo formal y salarios promedios reales". Tesis de maestría. Universidad Nacional Autónoma de México (UNAM) México.

Segovia, Alexander 1999 "La actuación y las políticas macroeconómicas a partir de 1989" en Boyce, James (coord.) Ajuste hacia la Paz. La política económica y la reconstrucción de posguerra en El Salvador (México: Plaza y Valdez/PNUD).

Segovia, Alexander 1999 "La economía de la guerra de los años ochenta" en Boyce, James (coord.) Ajuste hacia la Paz. La política económica y la reconstrucción de posguerra en El Salvador (México: Plaza y Valdez/PNUD). 